\title{
Intestinal Spirochetosis in an Immunocompetent Patient
}

\author{
Patricia Guzman Rojas ${ }^{1}$, Jelena Catania ${ }^{2}$, Jignesh Parikh ${ }^{3}$, Tran C. Phung ${ }^{4}$, Glenn Speth ${ }^{5}$ \\ 1. Internal Medicine, UCF College of Medicine 2. Infectious Diseases, Orlando Va Medical Center, UCF \\ Com/hca Gme Consortium's Internal Medicine Residency Program 3. Pathology, Orlando VA Medical \\ Center 4. Infectious Diseases, Orlando VA Medical Center 5. Gastroenterology, Orlando VA Medical \\ Center
}

$\square$ Corresponding author: Patricia Guzman Rojas, patricia.guzman@upch.pe Disclosures can be found in Additional Information at the end of the article

\section{Abstract}

Intestinal spirochetosis (IS) is an infestation defined by the presence of spirochetes on the surface of the colonic mucosa. The implicated organisms can be Brachyspira aalborgi or Brachyspira pilosicoli.

We present the case of a 66-year-old man with a past medical history of diabetes mellitus, hypertension, morbid obesity, and gastroesophageal reflux. The patient was sent to the gastroenterology clinic for a screening colonoscopy due to a prior history of colonic polyps. The patient was completely asymptomatic as he denies any abdominal pain, diarrhea, melena, or hematochezia. A colonoscopy was done showing colitis in the cecum and the ileocecal valve, for which random biopsies were taken in the terminal ileum, cecum, and ascending colon. The histopathology result was positive for spirochetosis. Due to this finding, the patient was referred to the infectious diseases clinic, where a rapid plasma reagin (RPR) and human immunodeficiency virus (HIV) tests were found to be negative. Since the patient was immunocompetent and asymptomatic, it was decided to monitor and not initiate antibiotic treatment.

Human IS are not related to non-intestinal spirochetes like Treponema pallidum. An infection of T. pallidum leads to a malignant picture called syphilitic proctitis and appears in the setting of an immunocompromised patient. The treatment of IS is based on the clinical presentation, severity of symptoms, and immune status. The purpose of this case is to emphasize the correct antibiotic indication in patients with IS.

Received 12/27/2017

Review began 01/17/2018

Review ended 03/14/2018

Published 03/15/2018

\section{C) Copyright 2018}

Guzman Rojas et al. This is an open access article distributed under the terms of the Creative Commons Attribution License CC-BY 3.0., which permits unrestricted use, distribution, and reproduction in any medium, provided the original author and source are credited.
Categories: Gastroenterology, Infectious Disease

Keywords: spirochetes, colitis, spirochetosis

\section{Introduction}

Intestinal spirochetosis (IS) is the presence of spirochetes on the surface of the intestinal mucosa and was first described in 1967 [1]. The implicated organisms can be Brachyspira aalborgi or Brachyspira pilosicoli [2-4]. Brachyspira aalborgi is a non-pathogenic commensal and Brachyspira pilosicoli can become an opportunistic pathogen. Spirochetosis can affect up to $5 \%$ of healthy people, this prevalence is found to be higher in patients from India or other parts of Asia [5].

\section{Case Presentation}




\section{Cureus}

We present the case of a 66-year-old man with a past medical history of diabetes mellitus, hypertension, morbid obesity, and gastroesophageal reflux disease. He was sent to the gastroenterology clinic for a screening colonoscopy due to a personal history of polyps and mild anemia (hemoglobin of $12.6 \mathrm{mg} / \mathrm{dL}$ ). The patient also had a positive family history of colorectal cancer. He was completely asymptomatic, denying any diarrhea, melena, hematochezia, or increased mucus in stool.

A colonoscopy was done showing severe diverticulosis in the distal descending colon, mid descending colon, and sigmoid colon. There was evidence of colitis in the cecum and at the ileocecal valve for which random biopsies were taken in the terminal ileum, cecum, and ascending colon (Figure 1). The biopsy from the cecum was positive for mild chronic nonspecific inflammation and Warthin-Starry stain was positive for spirochetosis (Figure 2).

Due to the findings, the patient was referred to the infectious diseases (ID) clinic where rapid plasma reagin (RPR) and human immunodeficiency virus (HIV) tests were ordered. Both of them were negative. Since the patient did not have any complaints, the ID clinic decided to monitor the patient and no antibiotic treatment was given.

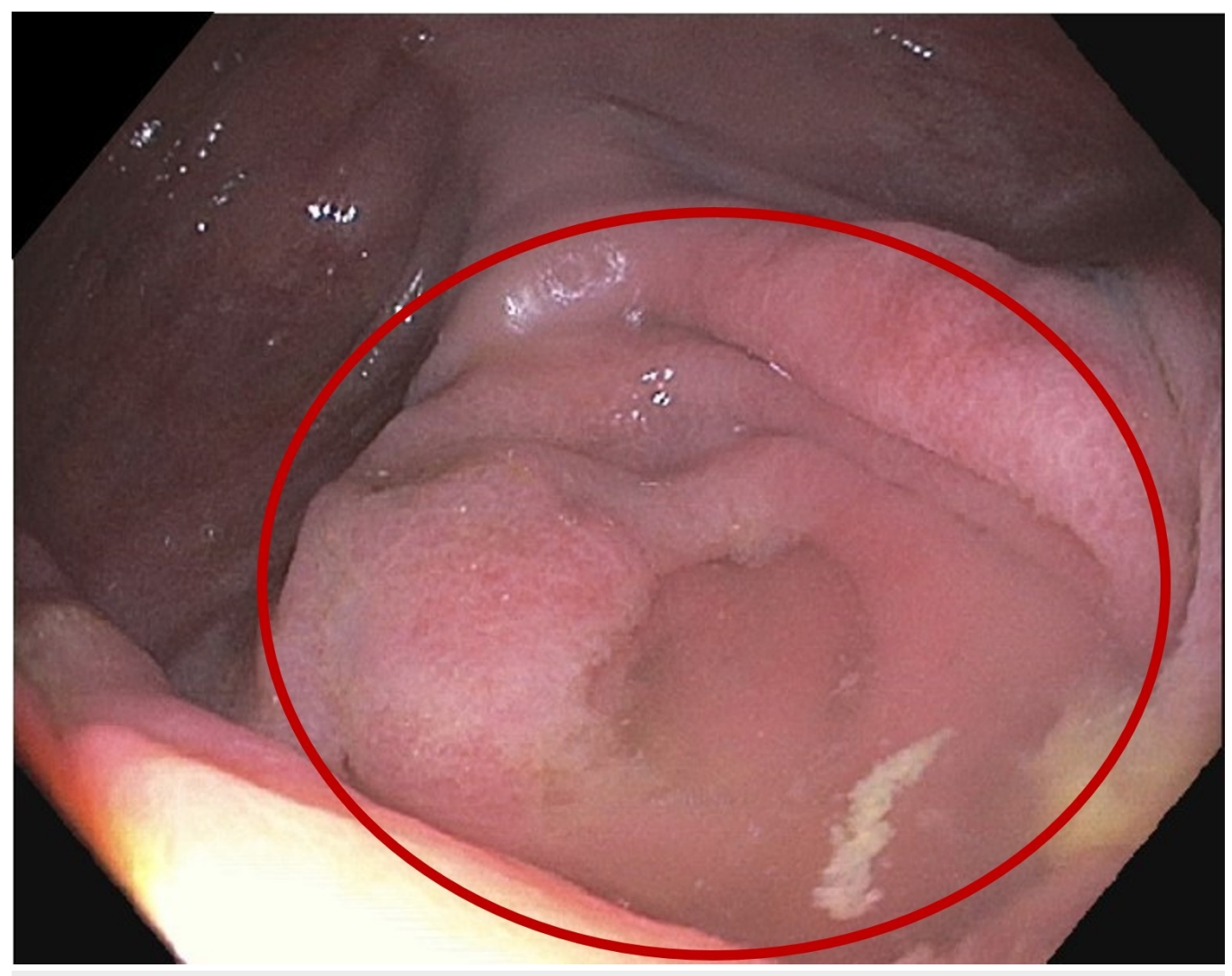

FIGURE 1: Colonoscopy showing cecum inflammation 


\section{Cureus}

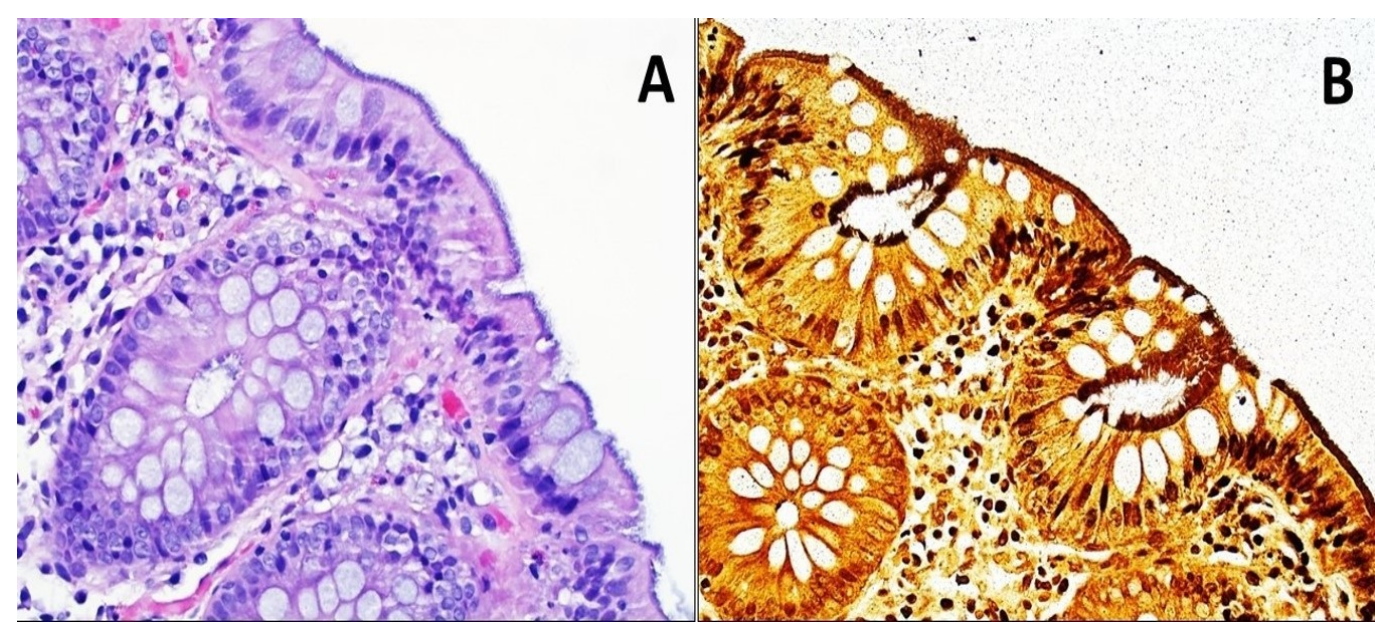

\section{FIGURE 2: Hematoxylin and eosin (H\&E) stain}

Hematoxylin and eosin stained section of the colonic biopsies showed filamentous structures on the surface epithelium forming a thick bluish fringe (Figure A).

A Warthin-Starry silver stain highlighted filamentous organisms (Figure B).

\section{Discussion}

Spirochetes can be classified into three different families: Spirochaetaceae (Borrelia, Spirochaeta, Spironema, Treponema), Leptospiraceae (Leptonema, Leptospira), and Brachyspiraceae (Brachyspira, Serpulina) [2]. As mentioned above, the two members of the Brachyspiracea family, B. aalborgi and B. pilosicoli, are associated with IS. Infection with these bacteria follows the fecal-oral route. Furthermore, $B$. pilosicoli is a zoonotic bacterium capable of being transmitted from animals to humans via handling or ingesting meat from infected animals [4].

As in our patient, IS is commonly discovered during a screening colonoscopy in an asymptomatic patient. If the patient becomes symptomatic, he can present with chronic watery diarrhea and/or abdominal pain [6]. Even though IS leads to mild/moderate clinical picture, there are cases where this has been associated with a severe and fatal evolution [2].

Colonoscopy findings are not specific as it can display a polypoid lesion, an erythematous area, or normal mucosa [7]. The diagnosis is made by pathology evaluation of the tissue (the typical histological feature is consistent with a band-like growth of spirochetes, adherent to the colonic luminal surface which is 3-6 um thick). This finding can be seen in the hematoxylineosin (H\&E) stain; however, Warthin-Starry or Dieterle silver impregnation are stains used for further clarification [2]. An alternative method for diagnosis is the polymerase chain reaction (PCR) test, which targets the 16S rRNA, NDAH-oxidase, and the 23rd DNA gene specific for $B$. pilosicoli, B. hyodysenteriae, and S. intermedia [8].

Human IS are not related to non-intestinal spirochetes like Treponema pallidum which causes a more malignant picture called syphilitic colitis/proctitis and appears in the setting of an immunocompromised patient. Syphilitic proctitis can cause a tumor-like lesion, hematochezia, tenesmus, or mucous discharge as a clinical picture and mostly affects the rectal area; it begins with an inflammation (endoscopic appearance of erythema, edema, or erosions) that can lead to extensive ulceration. Histologic evaluation can elicit a dense mononuclear cell infiltrate with prominent plasma cells. Granulomas and obliterative endarteritis may be present [9-10]. 
Treatment of IS must be based on the clinical presentation, severity of symptoms, and immune status. Eradication of symptoms has been reported with metronidazole $500 \mathrm{mg}$ four times a day, for 10 days; however, immunocompetent/asymptomatic patients can be clinically monitored without any initiation of antibiotic treatment [2]. There is no data stating a need for stool studies or repeat colonoscopy.

\section{Conclusions}

The intention of this case is to emphasize the correct antibiotic indication in patients with IS. Moreover, physicians should be aware of the patient's symptoms and comorbidities/immune status.

\section{Additional Information \\ Disclosures}

Human subjects: Consent was obtained by all participants in this study. Conflicts of interest: In compliance with the ICMJE uniform disclosure form, all authors declare the following: Payment/services info: All authors have declared that no financial support was received from any organization for the submitted work. Financial relationships: All authors have declared that they have no financial relationships at present or within the previous three years with any organizations that might have an interest in the submitted work. Other relationships: All authors have declared that there are no other relationships or activities that could appear to have influenced the submitted work.

\section{References}

1. Harland WA, Lee FD: Intestinal spirochetosis. BMJ. 1967, 3:718-719. 10.1136/bmj.3.5567.718

2. Tsinganou E, Gebbers JO: Human intestinal spirochetosis - a review . Ger Med Sci. 2010, 8:7. $10.3205 / 000090$

3. Brooke CJ, Riley TV, Hampson DJ: Comparison of prevalence and risk factors for faecal carriage of the intestinalspirochaetes Brachyspira aalborgi and Brachyspira pilosicoli in four Australian populations. Epidemiol Infect. 2006, 134:627-34. 10.1017/S0950268805005170

4. Smith JL: Colonic spirochetosis in animals and humans. J Food Prot. 2005, 68:1525-34.

5. van Mook WN, Koek GH, van der Ven AJ, Ceelen TL, Bos RP: Human intestinal spirochaetosis: any clinical significance?. Eur J Gastroenterol Hepatol. 2004, 16:83-87.

6. Ngwa T, Peng JL, Choi E, Tayarachakul S, Lianpunsakul S: Colonic spirochetosis in a 60-year old immunocompetent patient: case report and review. J investing Med High Impact Case Rep. 2016, 4:10.1177/2324709616662671

7. Alsaigh N, Fogt F: Intestinal spirochetosis: clinicopathological features with review of the literature. Colorectal Dis. 2002, 4:97-100. 10.1046/j.1463-1318.2002.00284.x

8. Lin RK, Miyai K, Carethers JM: Symptomatic colonic spirochaetosis in an immunocompetent patient. J Clin Pathol. 2006, 59:1100-1. 10.1136/jcp.2005.034900

9. Yang JF, Peng L, Siddiqui AA, Mayorga CA: Syphilitic proctitis. Proc (Bayl Univ Med Cent). 2016, 29:327-328.

10. Teitelman M, Wilson JA, Guy CD: Syphilitic proctitis. Clin Gastroenterol Hepatol. 2008, 6:A26. 10.1016/j.cgh.2007.12.031 